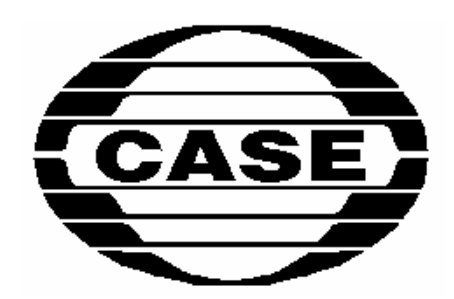

Center for Social \& Economic Research

\title{
LABOUR MARKETS \\ AND WAGES POLICIES DURING ECONOMIC TRANSITION
}

by

Jacek Rostowski

Warsaw, July 1994 
Materials published in this series have a character of working papers which can be a subject of further publications in the future. The views and opinions expressed here reflect Authors' point of view and not necessary those of CASE .

Paper was sponsored by Stefan Batory Foundation.

Copyright (C) by CASE Research Foundation, Warsaw 1994

ISBN 83-86296-10-0

Editor:

CASE - Center for Social \& Economic Research

00-585 Warszawa, Bagatela 14

tel/fax (48-2) 62865 81; tel/fax (48-22) 294383 


\section{Introduction.}

Arguments in favour of wage controls in Post-communist economies have changed considerably since the issue was first addressed in the late 1980s [Rostowski 1989 and 1990]. Then it was suggested that Latin American experience showed that wage controls were necessary during stabilization [Fischer 1988]. Two kinds of argument were put forward: the first centering on the danger of increases in the real wage upon stabilization, the second on controls (both wage and price) as a mechanism for co-ordinating expectations. Indeed, it was believed that if such controls were combined with the fixing of the exhcange rate, balancing the budget and bringing monetary emission under control, then "virtually costless stabilization is possible."

While price controls were rejected as inappropriate for PCEs, wage controls in the form of tax based incomes policies (TIPs) with very high marginal tax rates became almost standard in the Central European stabilizations (e.g. Poland 1990, Czechoslovakia 1991). The justification given was often that, whatever the case in other regions such as Europe or Latin America, the absence of private owners interested in maximizing returns on capital meant that, in the absence of wages policies, real wages would be excessive given the requirements of stabilization. We shall examine these claims in Section 4. Once stabilization was largely completed by the mid-1990s, those arguing in favour of wage control claimed it continued to be necessary as long as a large part of manufacturing industry remained in state hands, in order to prevent the decapitalization of the economy (i.e. effectively negative net investment). We shall examine the argument for wage control in the longer term in PCEs in Section 5.

\section{The Pazos-Simonsen Mechanism: short term wage controls as a means of abrogating existing wage contracts.}

For any group of workers in an inflationary situation the real wage reaches a peak of $\mathrm{w}^{*}$ at the beginning of each period of $h$ months for which the nominal wage is fixed [Dornbusch and Simonsen 1988]. As inflation occurs at a rate p percent a month, the real wage declines in value until the end of $h$, when it is once again increased to $w^{*}$ (see Figure 1).

The average real wage is given by:

$$
\mathbf{w}=\mathrm{w}^{*}\left[(1+\mathrm{p})^{\mathrm{h}+1}-1\right] /\left[(\mathrm{h}+1) \mathrm{p}(1+\mathrm{p})^{\mathrm{h}}\right]
$$

So that an increase in the rate of inflation $\mathrm{p}$, or the lengthening of the period of indexation h, leads to a fall in the real wage [Modiano 1988]. 
FIGURE 1

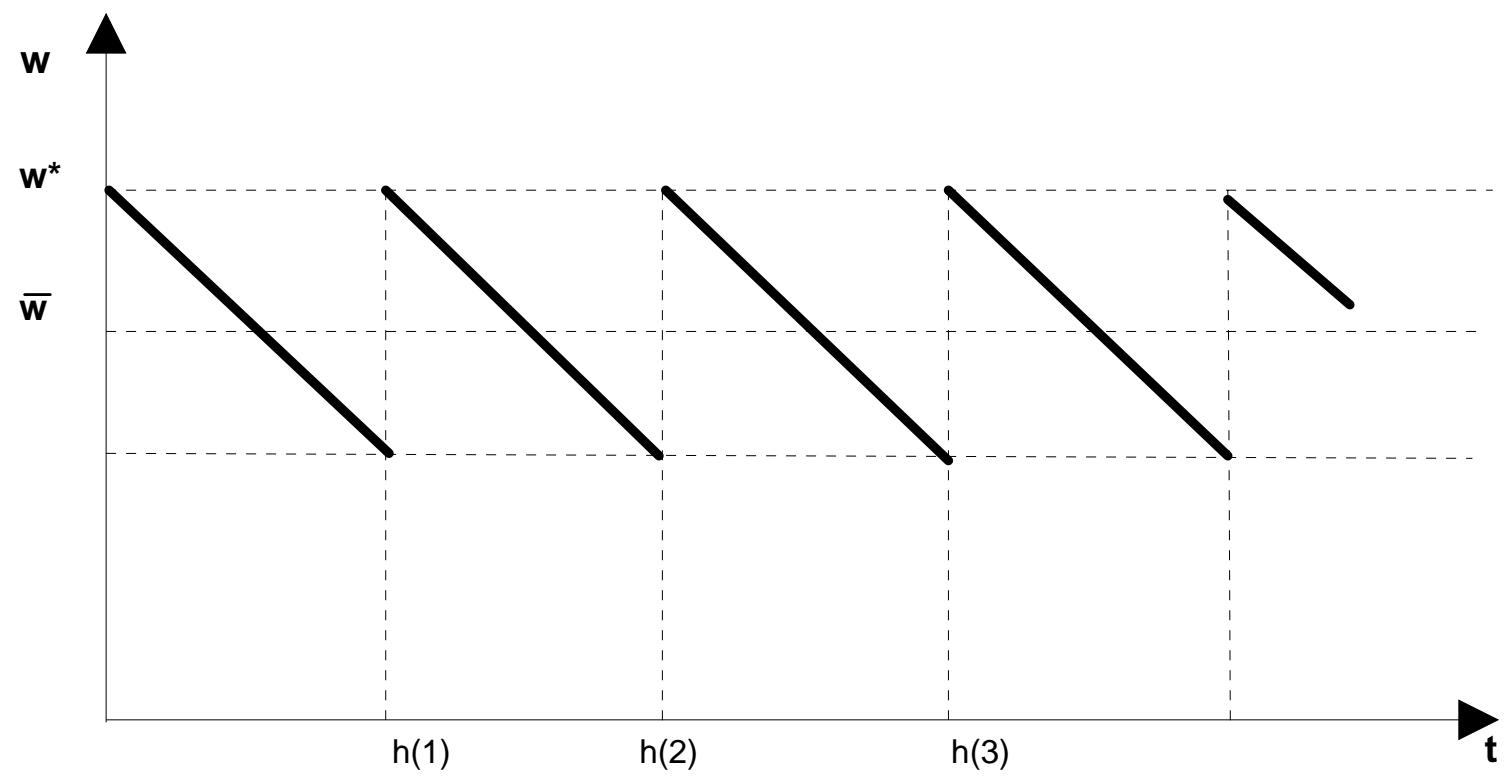

If the indexation period is synchronized across the economy, so that different groups of workers start $\mathrm{h}$ at the same time, then if inflation is stopped overnight at $\mathrm{t}_{\mathrm{i}}$ at the beginning of $\mathrm{h}$, then the average wage of all workers in the economy will increase to its peak value $\mathrm{w}^{*}$. Such an increase will obviously be unsustainable if the economy is an open one. If the exchange rate is fixed the country will begin to run a current account deficit which will ultimately become unsustainable. If the exchange rate floats, the currency will depreciate, raising prices, reducing the real wage, and causing demands for nominal wage increases at the end of $\mathrm{h}$, which will feed into further inflation.

Nor does the increase in the average real wage depend on stabilization happening at the beginning of a new indexation period. If nominal wage increases occur automatically - as a result of pre-existing wage contracts - to compensate workers for the inflation which occurres between the beginning of $h$ and the moment of stabilization, then the average real wage will increase irrespective of when the stabilization takes place relative to the beginning of $h$. Under the circumstances described in this paragraph wage control is needed above all as a mechanism for abrogating pre-existing wage contracts [Fischer 1988] ${ }^{1}$.

If the indexation period is not synchronized across the economy, so that different groups of workers start $h$ at different times $t_{1}, t_{2}$, etc., then if inflation is stopped overnight at $t_{i}$ and at the same time pre-existing contracts result in nominal wage increases to compensate those

\footnotetext{
1 "This is the serious reason for intervention in the wage setting process." Of course, if wage contracts were abrogated and if inflation were stopped just halfway through $\mathrm{h}$, then the average real wage would remain constant, and if this happened just before $t_{\mathrm{i}}$ the average real wage would fall.
} 
workers whose indexation period started before $t_{i}$ for the inflation which occurred between the beginning of their $h$ and $t_{i}$, then the average wage of all groups of workers will again increase to their peak value $w^{*}$. As a result the average real wage in the economy will rise sharply, with the consequences described earlier, unless inflationary wage contracts are abrogated through wage controls.

The above justification of wage controls has been used to justify price controls, on the grounds that otherwise trade unions will not agree to to the abrogation of wage contracts [Bruno 1989]. The logic, though, is unclear. If trade unions understand that their members average real wage has not been $\mathrm{w}^{*}$ but in fact $\mathbf{w}$, and if they are prepared to accept the latter, then there is no need for price control. With the old wage agreements abrogated and the authorities stopping inflation through suitable financial policies, real wages will settle automatically at $\mathbf{w}$ (effectively prices will adjust to the frozen nominal wages to generate the correct average real wages $)^{2}$. If on the other hand trade unions are unwilling to accept $\mathbf{w}$, then no agreement on the level at which prices are to be frozen will be possible in any case.

A critical, and usually unspoken assumption, of advocates of wage controls is that monetary and fiscal policies are simultaneously tightened, so as to ensure that the equilibrium wage is not higher than that embodied in the controls. If this were not the case, the authorities would find themselves trying to maintain the controls against a market in which both suppliers of labour and its purchasers were willing to settle on a higher wage. Achieving such a goal is, however, likely to be far from easy. Policy makers are unlikely to know what equilibrium average nominal wage corresponds to what degree of fiscal and monetary tightness. This is particularily the case when the inflation being stabilized is very high. The argument for wage control is often, therefore, phrased in terms of forcing nominal and real wages below equilibrium level, and therefore achieving stabilization at a lower cost in terms of unemployment and lost output. The question then comes down to whether one believes that the government is in fact able to enforce such a wages policy. The experience of many countries (including the UK in 1973 and 1979) has shown that success is very unlikely.

Even if demand management policy is such as to ensure that the controlled wage is at or above equilibrium (i.e the wage controls acts exclusively to abrogate outdated contracts and not to repress wages), the question remains which of the potential equilibrium average real wages should be chosen. This is mainly a question of the economy's external balance. The higher the real wage the smaller the payments surplus (see Figure 2).

\footnotetext{
${ }^{2}$ However, it is important that the frozen nominal wages and the fixed exchange rate be compatible with $\mathbf{w}$.
} 
FIGURE 2

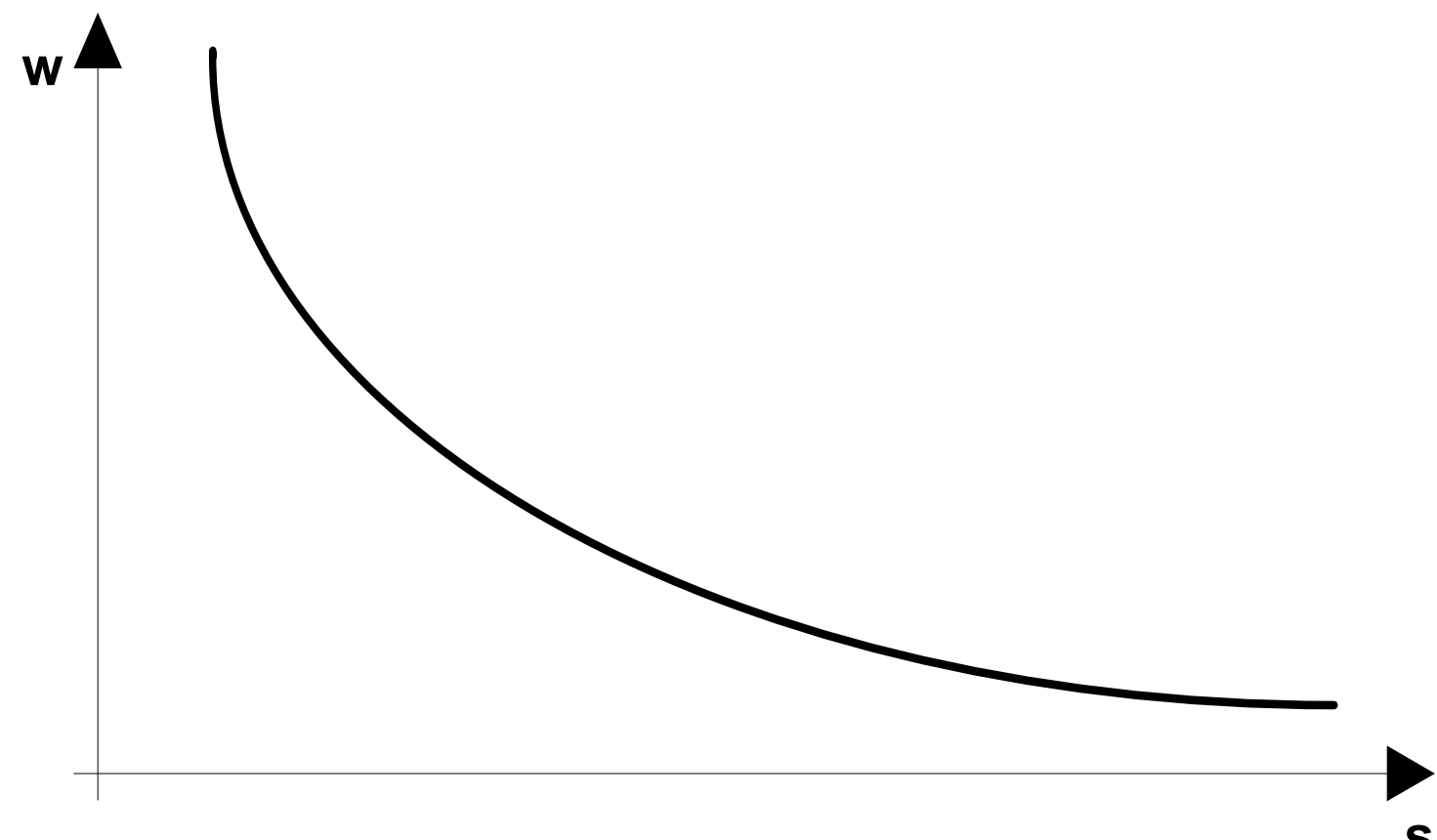

$\mathbf{S}$

\section{Short Term Wage Controls as a Mechanism for Co-ordinating Expectations.}

Fischer [1988] makes this point strongly. If the government sets a low inflation rate when economic actors expect it to continue at a high rate the result is recession. This is essentially the case of a non-credible stabilization programme. The possible actions of government and expectations of economic actors, together with the economic outcomes that result from each combination are given in Table 1:

TABLE 1

Economic Actors

High inflation

Government causes:

expect:

\section{Low inflation}

High inflation

Hyperstagflation

Recession

Low inflation

High employment

Stabilization

hyperinflation

Source: Fischer 1988.

Since the government cannot know whether economic actors will believe in its programme, i.e. whether the result will be stabilization or recession, it should impose wage 
(and price controls!) as well as fixing the exchange rate. In this way it guarrantees to the economic actors that in the short term inflation will indeed be low. The economic actors supply and demand quantities - and also set any free prices - accordingly, and stabilization without recession is achieved. The argument in this case is rather different from that in the previous section: it is not just a matter of abrogating pre-existing contracts which would otherwise lead to disequilibrium prices, but rather of changing expectations which would cause new contracts to be set in such a way as to generate a high unemployment/low output outcome.

Two problems arise. The first is that unlike in Latin America or Israel, the bulk of prices in communist economies before transition had been controlled for decades. As a result in many countries there was a large monetary overhang, while in others relative prices had become so distorted that there was a generalised expectation that they would soon be freed. This expectation aggravated the already existing shortages, making perseverence with price control impracticiable. Far from helping to change inflationary expectations, in postcommunist economies price controls actually fuelled them. This is because they increase demand and reduce supply by pricing goods at the old low prices, which are certain to be raised in the future. Also, after decades of price controls, it is unrealistic to imagine that the authorities could know what at level to set relative prices.

Second, with prices free it is not clear that wage controls would be likely to add significantly to the authorities' ability to affect economic actors inflationary expecectations. Although wages might affect prices in the medium term, in the very short term other factors, such as the exchange rate or increases in administered prices of important inputs such as energy, are likely to be more important. Indeed, in Poland in 1990 prices soared far ahead of wages during the first quarter of the stabilization programme, so that wage controls are unlikely to have been important in forming inflationary expectations ${ }^{3}$.

\section{Short Term Wage Controls in Semi-heterodox Stabilization Programmes in PCEs.}

Stabilization programmes have conventionally been classified according to whether they are shock or gradual, orthodox or heterodox. Of course, there has been considerable disagreement as to what constitutes orthodoxy or otherwise. Orthodox plans must include: (1) balancing the budget; and (2) bringing nominal monetary growth under control - although real money balances may increase sharply as a result of remonetization of the economy (Chapter 10). If inflation has been very high, orthodox plans must also include the fixing of the

\footnotetext{
${ }^{3}$ Wages also rose less than the amount permitted by the wage controls - a point to which we return below.
} 
exchange rate (Chapter 3). Heterodox plans on the other hand must include: (1) price and wage controls; and (2) fixing the exchange rate. However, it is admitted by supporters of the heterodox approach that if such plans are to be successful in the medium term they must also include responsible - that is orthodox - fiscal and monetary policy. Of the three attempted "heterodox shock" stabilizations of 1985, those in Argentina and Brazil failed because they did not "get the fundamentals (fiscal and monetary policy) right", while Israel was successful because it did [Bruno, Di Tella, Dornbusch and Fischer, 1988]. Thus, the key difference between orthodox and heterodox plans is the presence in the latter of price and wage controls.

How then should we classify the various stabilization programmes in PCEs? All the countries which stabilized (and some which did not) freed prices rather than controlling them. Poland (January 1990) and Czechoslovakia (January 1991), which had wage controls and fixed exchange rates, can be thought of as semi-heterodox - because prices were freed. Bulgaria (February 1991) had wage controls and a floating exchange rate, so that one can only call it semi-heterodox/semi-orthodox! Hungary (1990-2) was clearly "gradualist orthodox" as it had no wage controls, in spite of the fact that its exchange rate float was dirty. Estonia (June 1992) was orthodox (fixed exchnage rate, no wage controls), while Latvia (October 1992) was maybe "super-orthodox" (no wage controls and a floating - though dirty exchange rate). Russia's failed stabilization of January 1992 was also "super-orthodox" - even the exchange rate float was only minimally dirty, as the authorities had hardly any reserves. This was the curious case of an orthodox stabilization programme which failed because it did not "get the fundamentals right". Much the same is true of the Russian attempt of early 1994 (see the Appendix for an attempt to classify all the stabilizations in the region, including an attempt to assess to what degree the programmes were "shock").

As can be seen, the variety of approaches in the region has been considerable. Nevertheless, the semi-heterodox shock stabilization of the Polish and Czechoslovak type was an innovation unique to the region, and it has been justified as being particularily suited to the nature of PCEs. In PCEs prices have to be liberalized so as to "get relative prices right", and in order to eliminate any monetary overhang that may exist. Thus stabilization must be accompanied by price liberalization rather than price control. The argument in favour of wage controls in PCEs therefore owes little to the idea that inflationary expectations need to be coordinated.

The main arguments in favour of wage controls in Central Europe were as follows. First, there was the feeling, particularily strong in the Polish case where wages were set monthly by managements highly dependent on workers' councils, that very tight wage controls at the beginning of the programme would help to break inflationary inertia of the kind discussed in Section 2. Nevertheless as we have seen, in Poland wages failed to increase 
up to the thresholds permitted by the TIP, indicating that the policy did not in fact fulfill this function. Second, there was a crude cost-push view of inflation, which was particularily widespread among officials inherited from the Communist regime. The weakness of this approach has been discussed at length in Chapter 2 .

Third, there was a slightly more sophisticated version of cost push (which was widespread among politicians, officials and advisers) which rested on the belief that enterprises might play a game of "chicken" with the authorities, paying out large wage increases and financing these either by running up bank or inter-enterprise debt [Rostowski 1993a]. The authorities would then be in a position in which they would have either to countenance the bankruptcy of a large part of industry, or to validate enterprise behaviour by creating domestic credit (making any subsequent stabilization attempt even less credible). This danger requires that there be at least a tacit "conspiracy of enterprises", since the authorities can afford to close down any enterprise on its own, or a small number of enterprises. This danger was particularily worrying as, at this early stage of the transition there were practically no mechanisms to select enterprises according to whether their financial problems were fundamental (solvency) or transitory (liquidity). The problem with this argument is that the mechanism used to control wages, the TIP, provides no real protection against the threat it is supposed to meet. If enterprises raise wages excessively, then their obligations under the TIP (which are not paid immediately) involve an even greater likelyhood of bankruptcy and mean an even further going climbdown by the authorities if they are forgiven.

The fourth argument used is that wage controls reduce the cost of the marginal worker and therefore reduce unemployment. This was clearly not relevant in Poland in 1990, when enterprises could choose whether the TIP should apply to their average wage or to their wage bill. The bulk chose the latter, and were thus encouraged to increase average and marginal wages while reducing employment. Indeed, the authorities allowed this quite consciously, realising that many enterprises were grossly overstaffed. This is quite typical of what has happened in successful PCE stabilizations. Stabilization and liberalization have occurred simultaneously with the first appearance of unemployment, with the latter being the unavoidable bye-product of the new regime in the labour market which allows labour to be reallocated to more efficient uses, particularily in the private sector [Rostowski 1993c]. Furthermore, one should not try to discourage the growth of unemployment at the beginning of a stabilization programme, as unemployment must reach - and probably exceed - the NAIRU if inflation is to be stopped [Rostowski 1989]. 


\section{Medium Term Wage Controls in Semi-shock Stabilization Programmes in PCEs.}

With the exception of Yugoslavia (1994), none of the stabilizations in PCEs have been "full shock" stabilizations in the sense that inflation was stopped completely in a matter of a few months. In this they differ from the stabilizations of the 1920s [Rostowski and Shapiro, 1992], and from the Bolivian hyperinflation of 1985 [Morales, 1988]. The reason for this is that in the PCEs none of the inflations, again with the exception of Yugoslavia (1994), reached rates at which prices were so flexible (both up and down) that the inflations could be stopped almost overnight by fixing the exchange rate and backing the currency [Rostowski 1990 and 1994]. In all these cases inflation continued at rates above $20 \%$ per annum for at least two years after the stabilization programme began. It is therefore useful to think of the standard PCE programmes as "semi-shock", in which inflationary concerns remain at the heart of policy making for a number of years after the initial stabilization.

Thus, in this medium term context of a year and more after the beginning of the stabilization programme, the effects of wages policies in distorting labour markets become important. Freezing wages over a number of years would clearly destroy the finctioning of the labour market completely, and is thus impossible in PCEs where one of the main requirements during the transition is to restructure the economy. However, even TIPs have an important distortionary effect in the medium term, although less so than wage freezes.

In order to see this we must first clarify a number of technical points regarding TIPs. If the economy is in a period in which inflation is declining, then any indexaton built into the TIP should be forward looking, i.e. wages in the firm should be allowed to rise by some fraction of the inflation in the period for which the wages are paid before the wages tax becomes payable, so that the tax free wage is given by:

$$
\mathrm{W}_{\mathrm{t}}^{*}=\mathrm{W}_{\mathrm{t}-1}^{*} * \mathrm{aP}_{\mathrm{t}}, \quad \text { where } \mathrm{a}<1
$$

If instead the wages free of wage tax were index by the inflation of the previous period, then nominal wages in any given period would be higher, real wages would be higher in the short term and inflation would be higher in the medium term. Instead of equation (2) we would have:

$$
\mathrm{W}_{\mathrm{t}}^{*}=\mathrm{W}_{\mathrm{t}-1} * \mathrm{P}_{\mathrm{t}-1} \text {. }
$$

The TIP would be binding only on the exceptional firms which wished to raise wages by more than inflation in the previous period (when it was higher than in the present one). The TIP would cease to be an anti-inflatonary tool, and for good or ill reducing inflaton would have to be left to orthodox tools (monetary, fiscal and exchange rate policy). On the 
other hand, the more one wishes to "bear down" on inflation by use of the TIP the lower should one set the parameter a in eq.(2). Thus in Poland in 1990 a was set at 0.3 in January, 0.2 in February and March, and 0.6 for the rest of the year (except for August when it was set at 1.0$)$.

Thus, if a $\ll 1$, as the vigorous use of the TIP as an anti-inflationary instrument requires, then given "forward looking" indexation as in eq.(2) the real wage which is free of the TIP must decline continuously. As a result, firms would only be able to respond to positive opportunities in the goods market in one of two ways before crossing the TIP threshold: (1) if the tax was based on increases in the total wage bill, firms could hire better workers by increasing the average wage in the firm by reducing the number of employees; or (2) if the tax was based on increases in the average wage in the firm, they could hire more workers with the same (or a lower) mix of skills, while ensuring that the average wage did not increase (or actually fell by the amount required by the parameter a) ${ }^{4}$. Thus firms could not expand both employment and improve the skill mix of their labour force without paying a price as a result of the TIP.

The above is not too much of a problem in the very short term, since PCEs start the transition from full employment, and thus almost all firms are overstaffed. Even in the short term, though, private sector firms can be expected to have the potential to expand - and this is one reason why the Polish authorities excluded the private sector from the operation of the TIP in early 1990. But in the medium term it can become a serious problem, since some state firms should continue to reduce output and employment, while other state firms should be increasing both and also the skills of their workforce.

It can, of course, be argued that if - as is the case in Poland but not in Czechoslovakia ${ }^{5}$ the private sector is free of the TIP, then firms which wish to expand in ways discouraged by the TIP, they can avoid the TIP if they become privatized. In this way the TIP can become an inducement for privatization. Although this may work in practice to induce some firms to cooperate in the privatization process, it is very much a second best argument, which confuses two separate issues: firms should be privatized irrespective of whether they wish to expand or contract production and employment, and those firms which have the opportunity to expand should do so irrespective of whether they are privatized.

\footnotetext{
${ }^{4}$ In Poland enterprises had to choose between the total wage bill or the average wage as the "object" of the TIP before the beginning of the tax year in 1990. Their choice would clearly be determined by their expectation as to whether they would be expanding or reducing employment. In 1991 the TIP for all enterprises was based on the average wage, The intention was to reduce the incentive to sack workers. The effect on unemployment seems to have been noticeable but very transitory, even though the previous choice was not restored.
}

${ }^{5}$ And after mid-1993 also not in the Czech Republic. 
Given these costs of a TIP in the medium term what are the arguments which have been advanced in its favour? The most important argument is probably that, even in the medium term, the TIP helps to either sustain investment in state owned firms (SOEs), or at the least to hinder their decapitalization. SOEs are either worker controlled as in Poland, or suffer from the absence of real owners who would have a clear pecuniary interest in resisting wage demands and defending the interests of capital within the firm. Even where managers of SOEs are appointed by the state as in the Czech Republic ${ }^{6}$, the state officials who appoint the managers are not personally interested in the return on capital, so the managers are similarily motivated. Even if managers received profit linked bonuses experience has shown that these count for little when weighed against the likelyhood of loosing one's job for having provoked a strike by resisting wage demands.

At the same time workers will wish to appropriate the whole of the firm's revenue. As Ward (1958) showed, they will wish to pay out their average product rather than their marginal product. If workers expect to remain in control of the firm for a significant period of time, then they may wish to pay out only average revenue after allowance has been made for the depreciation of the capital stock. In such a case the SOE will not have sufficient resources to expand through net investment. If workers expect to loose control of the firm soon, either because of privatization, redundancy or because they intend to depart for the private sector, then they will not even amortize the capital they consume during production. The firm will engage in negative net investment and will be decapitalised. In fact, the workers may sell off parts of the physical assets of the SOE so as to generate revenue which they can then divide among themselves. In this way they can accelerate the rate of decapitalization of the SOE far above the rate of depreciation of its physical assets ${ }^{7}$.

Thus the argument is that the TIP, by increasing the cost of wages when these exceed a certain threshold, increases the cost to workers of a zloty or crown going towards wages costs (apart from the tax, the cost of paying out a zloty in wages can be thought of as the reduction in investment, which reduces job security). In this way the TIP increases the attractiveness of spending that same zloty on investment in the firm ${ }^{8}$. In Figure 3 the TIP introduces a tax wedge between the marginal cost of wages (MCW) and the marginal benefit of wages (MBW), which is downward sloping as one would expect. The result is to reduce W/R, the share of wages in the firm's revenue.

\footnotetext{
${ }^{6}$ And previously Czechoslovakia.

${ }^{7}$ Maciejewski [1993] has calculated that about $17 \%$ of the revenue of SOEs in Poland comes from the sale of capital assets.

${ }^{8}$ On the assumption that the worker expects to be associated for at least some time to come with the firm. Those workers who expect to leave or be sacked will not be affected by the TIP, but will usually be in a minority.
} 


\section{FIGURE 3}

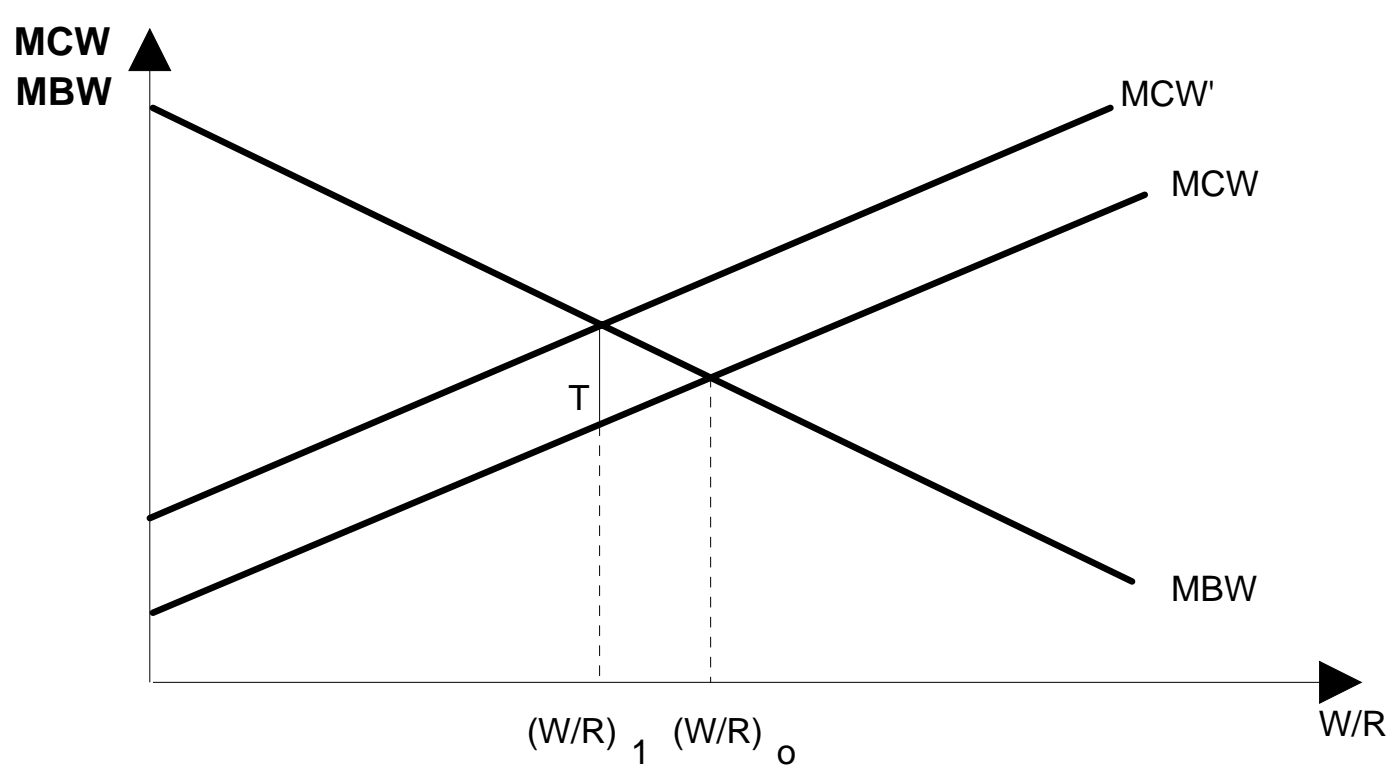

This argument has two weaknesses. The first is that it assumes that the effective wage within the firm can be controlled by controlling the nominal wage. In the context of the distribution of a firm's income between labour and capital, the effective wage can be defined as the money wage/unit of time*units of effort. In labour amanged or dominated firms the workforce can get around the restrictions resulting from a TIP either by reducing the hours they work every day (either openly or covertly), or by reducing the effort they make during the hours worked. In both cases production and revenue will decline. Thus although nominal wages remain the same so as to avoid the TIP, they will be obtained in exchange for a smaller number of hours worked with less effort.

The hours or strength saved may be used to earn additional income in a second job or may be spent on leisure. Wages (W) as a share of revenue (R) may reach much the same level as in the absence of a TIP. The difference is that $\mathrm{R}-\mathrm{W}$ approaches zero not as a result of a high W, but because of a low R. Although it is not the only reason, such an "effort effect" may well have been partially responsible for the fact that output fell so much more than employment in Polish industry in 1990. Clearly, R-W may remain somewhat above the level at which it would be without the TIP for two reasons: first, it may be hard to find part-time work outside the firm; second, the marginal cost of working with a given amount of effort when one is in the workplace may be relatively small. However, both kinds of rigidity is likely to decline over time, so that in the medium term the TIP is unlikely to act as an effective barrier to the decapitalization of SOEs. 
The second weakness of the decapitalization argument is that it assumes that nominal wages can be controlled effectively. We noted in Section 2 that governments which tried to maintain wages below equilibrium levels through wages policies usually found themselves unable to make the policies stick. This is because although employers are unwilling to pay wages above the marginal product of labour, they are also unwilling to pay below the marginal product of labour, if that means being unable to hire as much labour as they desired at a given moment. Thus only the government defends the wages policy if the controlled wage is below equilibrium ${ }^{9}$. In an economy dominated by labour managed or dominated firms, a government which attempts to prevent decapitalization of SOEs by use of a TIP also has no allies within the firms (and often no allies outside of the firms either!). This is because the equilibrium wage for each firm is determined by the employees themselves, and as we have seen depends mainly on their expected employment in, and control of, the firm. This does not mean that the government cannot control wage growth in SOEs, but that it can only do so through restrictive demand management. In doing this the authorities reduce firms revenue, leading to their decapitalization at a given wage.

Of course, the question needs to be asked whether the decapitalization of SOEs is such a bad thing during transition. When such decapitalization takes the form of divestment of assets by SOEs it leads to the "asset privatization" which has played a very important role in private sector development, for instance in Poland [Rostowski 1993c]. It is far from clear that such assets would be used more efficiently if they were privatized as part of an ongoing business. Even if the use of assets were were known to be more efficient after enterprise privatization than after asset privatization, which is not the case, asset privatization might still be preferred on the grounds that it happens far more rapidly.

It is often argued that the decapitalization of SOEs leads to an increased share of consumption and a reduced share of investment in GDP. However, as workers are more likely to decapitalize their SOE if they expect to cease working for it soon It is workers in such a situation are the ones who are particularily exposed to the risk of unemployment. Such workers will tend to have particularily high propensities to save, so it is far from clear that the consumption rate need rise. Savings need not be efficiently invested if the banking system lacks skills [Rostowski 1993b], but it is not clear why ploughback into SOEs should be much better than even the inefficient allocation of capital achieved by the banking system. A more serious problem is that the proceeds of asset privatization go to the SOE rather than to the state. A TIP ensures that a part (maybe even most) of the proceeds of asset privatization go to the state (unless the workers raise effective wages by reducing hours and effort).

\footnotetext{
${ }^{9}$ The wage controls can be brought in line with the equilibrium wage by tightening demand, but then the controls are no longer binding.
} 
A quite different argument in favour of TIPs has been advanced, based on the optimand of the labour managed firm. If workers expect to remain in control of the firm for a long period of time and to remain personally associated with the firm, then they may in fact engage in net investment. In such a case, however, they will tend to invest in more capital intensive technologies than would a capitalist owner. In this way an economy consisting of labour managed or labour dominated firms will generate a higher level of unemployment than a capitalist economy. A TIP which has as is object the average wage within firms will help to counteract this tendency, by increasing the cost of additional income for existing workers generated by new investment. Unfortunately, this is a weak argument in favour of the TIP as it will achieve this effect by discouraging the workers from investment altogether, rather than encouraging them to invest in more labour intensive technologies.

Another argument often advanced in favour of wage controls in the medium term in PCEs relates to so-called "wage chimneys". These are enterprises which have extremely high capital labour ratios, so that if wages were completely unconstrained they could rise within the firm to levels which would be outlandishly high. An example is the Plock Refinery in Poland, which at one time employed 10,000 people, but whose turnover was equivalent to 5 percent of the industrial sales of the whole country. When capital/employee is as vast as at Plock there is little danger of workers being able to achieve a significant decapitalization of the firm over a short period of time by reducing work effort or hours. A TIP is therefore likely to succeed here. The question is whether it is sensible to impose a TIP on all SOEs just because it is justified and workable in few massively capitalized firms. The TIP could be restricted to such firms, or alternatively, they could be made to pay a large capital charge.

There is one argument in favour of wage controls which is relevant, but which has not to my knowledge - been advanced. This is that wage controls, be they in the form of a TIP or not, provide a mechanism by which the authorities can pre-commit themselves strongly to stabilization. If the wages policy is breached then such a government defeat is visible to all, possibly leading to the fall of the government itself (as happened in the UK in 1973). Thus, when a government announces a wages policy it is forced to adopt monetary and fiscal policies which ensure that the controlled wage is at or below the equilibrium wage (i.e. that the policy is not binding), so as to help it to win any conflict with workers over the wages policy.

This is very much the role played by the TIP in Poland on at least two occasions: first in the autumn of 1990 and then in early 1991. The first episode occurred after a period when 
financial policies had been excessively loosened in June of $1990^{10}$. Combined with the political uncertainty resulting from the Presidential elections, this lead to severe strike pressure and the danger that SOEs would grant wage increases and incurr wage tax liabilities which they would be unable to meet. As a result, the government urged a sharp tightening of interest rate and credit policy on the National Bank of Poland, to which the bank acceded after considerable hesitation ${ }^{11}$. A second wave to labour unrest occurred in early 1991 as a result of expectations that the new Bielecki government would fulfill President Walesa's intimations that the TIP would be abolished. Again monetary policy was tightened to protect the TIP ${ }^{12}$.

Of course, the question arises as to whether precommitting to the exchange rate is not better than precommitting to a set of nominal wages implicit in a TIP. A very strong committment to the exchange rate, as with the kind of "high powered money board" arrangement discussed in Chapter 11 and implemented in Estonia and Lithuania, is probably superior to precommitting to a TIP. But if a country has not followed the Baltic path it is probably better for it to precommit to a TIP and a weakly fixed exchange rate than to precommit (weakly) only to the exchange rate. It is also possible that in countries with a strongly organized working class it may be advisable to precommit to something which makes it clear from the start that attempts by trade unions or workers' councils to undermine the stabilization programme will be faced down by the government.

\section{Reducing Inflationary Inertia by Lengthening the "Indexation Period" of the TIP.}

If we accept that a TIP will help to reduce inflation directly (i.e. not just through the "precommittment effect"), then the period for which the TIP thresholds remain constant in nominal terms should be lengthened as much as possible as inflation declines. In Figure 1 we saw that a shortening of the period of indexation of wages $h$ resulted in an increase in the real wage (at a given rate of inflation). Not surprisingly as inflation increases and the real wage falls, workers demand a shortening of $\mathrm{h}$ as compensation. As a result indexation periods

\footnotetext{
${ }^{10}$ A government may. of course, not understand this fact. This was the case in Britain in 1973, when wages policy was accompanied by an expansionary damand management policy with catastrophic results. It was also the case in Poland in teh summer of 1990, when monetary and fiscal policy were sharply loosened, while the wages policy remained unchanged. This resulted very quickly in significant labour unrest, and the reversal of financial policy.

${ }^{11}$ The government wanted the refinance credit interest rate increased from $35 \%$ per annum to $50 \%$ in October. The NBP raised the rate to $45 \%$ in October with the result that it then had to increase the rate to $56 \%$ in November, one week before the Presidential elections.

${ }^{12}$ This time the NBP was in favour of increasing the refinance interest rate to $75 \%$, while the government had doubts. Both sides were agreed that monetary policy had to be tightened, the question at issue was whether credit limits or interest rates should be the main instrument of that policy.
} 
become very short (often a month or less in very high inflations), with the result that any increase in prices is quickly transmitted to wages, thence to price and so on. The economy becomes very fragile as regards any resurgence in inflation.

In PCEs we are concerned with wages in SOEs. Since these are labour managed or dominated, they will shorten indexation periods as much as workers desire. The only way of controlling this is through the TIP. The object of the TIP is defined as either the wage bill or the average wage, and the threshold value of this variable at which the TIP begins to be paid is revalued in nominal terms every so often. In very high inflation countries this is often once a month, as was the case in Poland in 1990-1. By lengthening the period of indexation of the TIP threshold as inflation declines one achieves an effect similar to that of lengthening the contract period in a capitalist market economy [Blanchard and Layard 1992], reducing in this way the economy's inflation fragility ${ }^{13}$

\footnotetext{
${ }^{13}$ I was one of the advisers recommending such a course in Poland from March 1990 on. Although I returned to the subject each time the TIP was discussed, and it was changed in form and object several times during 1990-1, for some unknown reason the lengthening of the indexation period was the one change which it was impossible to get the bureaucracy of the Ministry of Finance to accept, though it was probably the only change in the TIP which would actually have been a clear improvement.
} 


\section{REFERENCES}

Blanchard,O. and Layard,R., "Post-stabilization Inflation in Poland",

Bruno,M., Di Tella,G., Dornbusch,R., and Fischer,S., 1988, Inflation Stabilization: the Experience of Israel, Argentina, Brazil, Bolivia and Mexico, MIT Press, Cambridge.

Bruno,M., 1988, "Sequencing Liberalization and Stabilization", in The Open Economy, eds

Dornbusch,R. and Simonsen,M., 1988, "Inflation Stabilization: The Role of Incomes Policy and of Monetization", in Dornbusch,R. Exchange Rates and Inflation, Cambridge MA, The MIT Press.

Fischer,S., 1988, "Comments on Helpmen and Leiderman", Carnegie-Rochester Series on Public Policy, 28, pp 85-92.

Modiano,E., 1988, "The Cruzado First Attempt: The Brazilian Stabilization Program of february 1986" in Inflation Stabilization: the Experience of Israel, Argentina, Brazil, Bolivia and Mexico, eds. Bruno,M., Di Tella,G., Dornbusch,R., and Fischer,S., MIT Press, Cambridge.

Morales,J-A., 1988, "Inflation Stabilization in Bolivia", in Inflation Stabilization: the Experience of Israel, Argentina, Brazil, Bolivia and Mexico, eds. Bruno,M., Di Tella,G., Dornbusch,R., and Fischer,S., MIT Press, Cambridge.

Rostowski,J. and Shapiro,J., 1991, "Secondary Currencies in the Russian Hyperinflation and Stabilization of 1921-24", London School of Economics, Centre for Economic Performance, Discussion Paper no. 59.

Rostowski,J., 1989, "Market Socialism is not Enough: Inflation vs. Unemployment in Reforming Communist Economies", Communist Economies, Vol.1, No.3.

Rostowski,J., 1990, "Stopping Very High Inflations in Reforming and Post-Communist Economies", Jahrbuch der Wirtschaft Osteuropas.

Rostowski,J., 1993a, "The Inter-enterprise Debt Explosion in the Former Soviet Union: causes, consequences, cures", Communist Economies and Economic Transformation, Vol.5, No.2.

Rostowski,J., 1993b, "Problems of Creating Stable Monetary Systems in Post-communist Economies", Europe-Asia Studies.

Rostowski,J., 1993c, "The Implications of Rapid Private Sector Growth in Poland", London School of Economics, Centre for Economic Performance, Discussion Paper no. 159.

Rostowski,J., 1994, "The Yugoslav Hyperinflation and Stabilization of 1992-4", mimeo, London. 


\section{Table of contents}

1. Introduction. 3

2. The Pazos-Simonsen Mechanism: short term wage controls as a means of

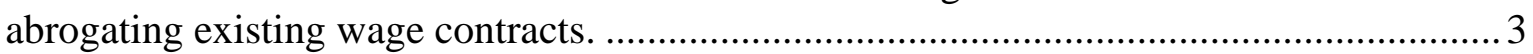

3. Short Term Wage Controls as a Mechanism for Co-ordinating Expectations. ................. 6

4. Short Term Wage Controls in Semi-heterodox Stabilization Programmes in PCEs......... 7

5. Medium Term Wage Controls in Semi-shock Stabilization Programmes in PCEs. ......... 10

6. Reducing Inflationary Inertia by Lengthening the "Indexation Period" of the TIP.......... 16

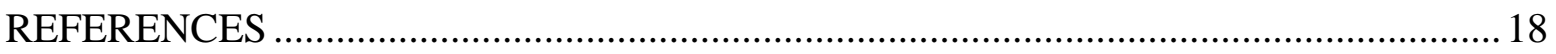

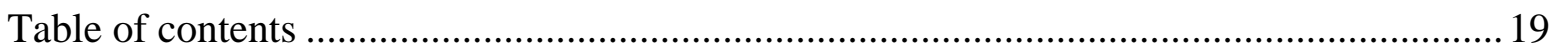

